\title{
Short communication concerning experimental factors affecting fission-track counts in apatite
}

\author{
Carolin Aslanian*, Raymond Jonckheere, Bastian Wauschkuhn and \\ Lothar Ratschbacher
}

Geologie, Technische Universität, Bergakademie Freiberg, 09599 Freiberg, Germany

5 Abstract. The tools for interpreting fission-track data are evolving apace but, even so, the outcomes cannot be better than the data. Recent studies that have again taken up the issues of etching and observation have shown that both have an effect on confined-track length measurements. We report experiments concerning the effects of grain orientation, polishing, etching and observation on fission-track counts in apatite. The results cannot be generalized to circumstances other than those of the experiments, and thus do not solve the problems of track counting. Our findings nevertheless throw light on the factors affecting the track counts, and thence the sample ages, whilst raising the question: what counts as an etched surface track? This is pertinent to manual and automatic track counts and to designing training strategies for neural networks. We cannot be confident that counting prism faces and using the $\zeta$-calibration for age calculation are adequate for dealing with all etching- and counting-related factors across all samples. Prism faces are not unproblematic for counting and other surface orientations are not per se useless. Our results suggest that a reinvestigation of the etching properties of different apatite faces could increase the range useful for dating, and so lift a severe restriction for provenance studies.

20 Summary. Fission tracks are damage trails from uranium fission in minerals, whose thermal histories are deduced from their number and length. A mineral is etched for observing the tracks with a microscope. We show that the etching and observation conditions affect the track count and explain it in the framework of a recent etch model. We conclude that established solutions do not secure that the ages and thermal histories inferred from track counts and measurements are accurate.

* corresponding author: Carolin.Aslanian@geo.tu-freiberg.de 


\section{Introduction}

Fission-track dating and temperature-time-path modelling are much-used thermochronological tools for geological research. The fission-track method rests on counting and measuring the lattice damage trails caused by uranium fission. Fission tracks in apatite are $\sim 20 \mu \mathrm{m}$ long (Bhandari et al., 1971; Jonckheere, 2003) and 10 nm wide (Paul and Fitzgerald, 1992; Paul, 1993; Li et al., 2011; 2012; 2014), thus too thin to observe with a microscope. Polished grain mounts are therefore etched to make them visible. Although it is important to understand etching for interpreting track data, it is often taken for granted that experimental factors related to etching and counting are inconsequential, e.g., that counting losses are negligible in slow-etching surfaces such as apatite prism faces. It is further assumed that systematic errors on the track counts cancel out if the sought ages are calibrated against those of age standards (e.g., $\zeta$-calibration; Hurford, 1990). We believe that, from lack of investigation, there persist certain misconceptions concerning these issues, which lead us to overestimate the accuracy of fission-track ages but also to impose undue practical restrictions, such as excluding all apatite grains not polished parallel to their $\boldsymbol{c}$-axes from the track counts and the confined-track measurements.

45 We report experiments aimed at furthering our understanding of fission-track counts and measurements in apatite. Because there is a subjective aspect to the counts (Enkelmann et al., 2005; Jonckheere et al., 2015) and measurements (Ketcham et al., 2015; Ketcham and Tamer, 2021), our numerical results cannot be generalized. They nevertheless reveal significant trends, which we endeavour to interpret in the context of recent etching models and to relate to practical dating issues.

\section{Experiments and Results}

We cut plane sections from Durango apatite crystals at $0^{\circ}$ (prism face; sample P00), 30 $0^{\circ}$ (B60) and $90^{\circ}$ (basal face; B00) to their $\boldsymbol{c}$-axes and mounted them in resin. We ground and polished them with 6, 3, and $1 \mu \mathrm{m}$ diamond suspensions and a $0.04 \mu \mathrm{m}$ silica suspension, and etched them in 10-s steps for 10,20 and $30 \mathrm{~s}$ in $5.5 \mathrm{M} \mathrm{HNO}_{3}$ at $21^{\circ} \mathrm{C}$. Reference points on the mounts allowed us to register the position of each investigated field and to return to it after each etch step. Each step, we counted the tracks at the exact same locations with a motorized Zeiss Z2m microscope and Märzhäuser stage controlled from a desktop computer running the Autoscan software.

Figure 1 and Table 1 compare the track counts at different etch times. Because the exact same 

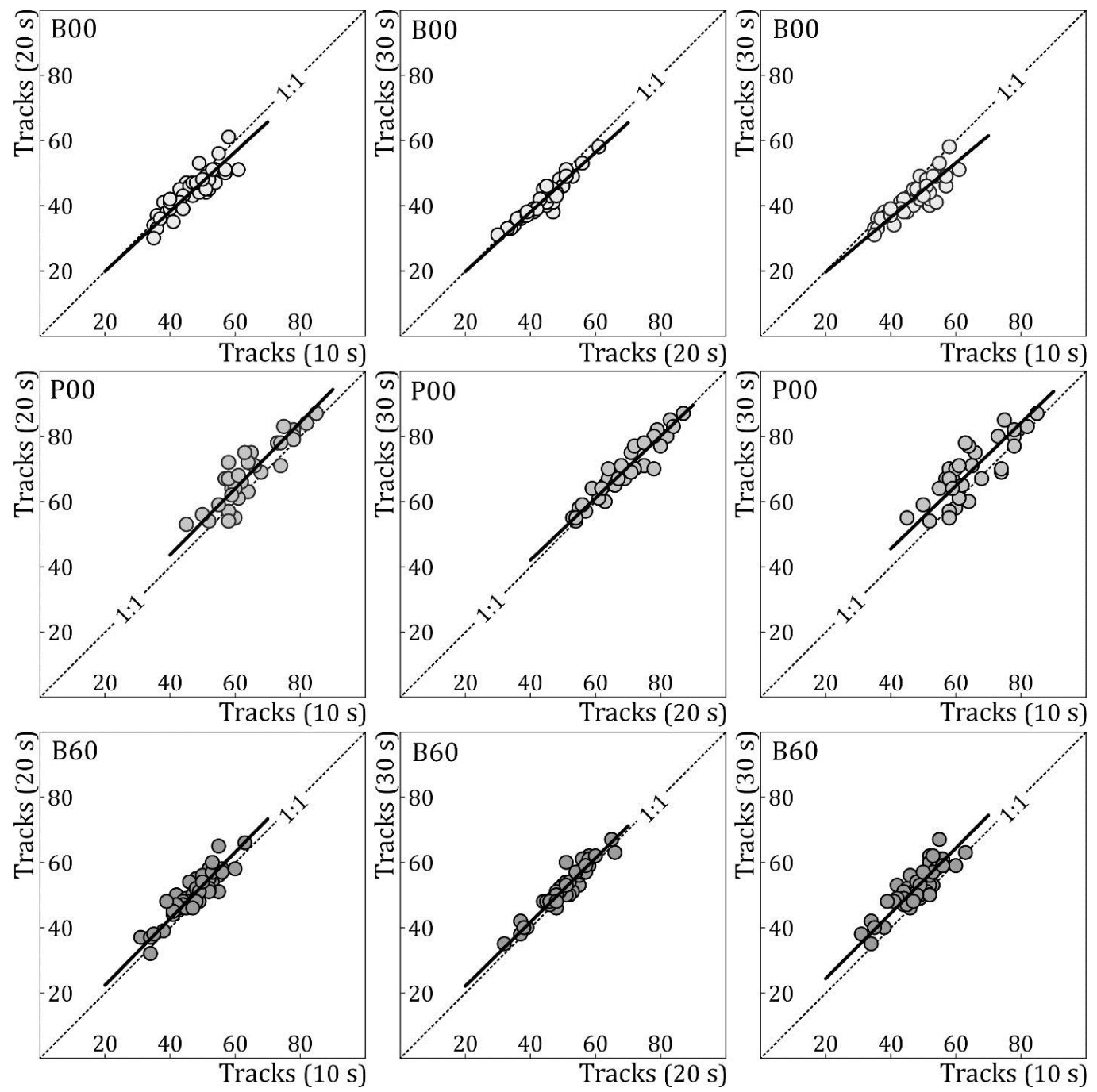

Figure 1. Comparison of repeat track counts after 10, 20 and $30 \mathrm{~s}$ etching $\left(5.5 \mathrm{M} \mathrm{HNO}_{3}\right.$ at 21 ${ }^{\circ} \mathrm{C}$ ) in the same areas of a basal face (B00), prism face (P00), and an intermediate face ( B60) of Durango apatite. 
Table 1. Repeat track counts after 10, 20 and 30 s etching in a basal face (B00), prism face (P00) and an intermediate face (B60) of a Durango apatite.

70

\begin{tabular}{llllll} 
Sample & $\mathrm{t}_{\mathrm{E}}(\mathrm{s})$ & Fields & Counts & $\rho_{\mathrm{S}}\left(\mathrm{TL} \mid 10^{6} \mathrm{~cm}^{-2}\right)$ & $\sigma / \sigma_{\mathrm{P}}$ \\
\hline B00 & 10 & 39 & 1824 & $0.123 \pm 0.003$ & 1.03 \\
B00 & 20 & 39 & 1732 & $0.116 \pm 0.003$ & 0.96 \\
B00 & 30 & 39 & 1600 & $0.110 \pm 0.003$ & 0.92 \\
\hline P00 & 10 & 32 & 2060 & $0.169 \pm 0.004$ & 1.20 \\
P00 & 20 & 32 & 2189 & $0.179 \pm 0.004$ & 1.18 \\
P00 & 30 & 32 & 2210 & $0.181 \pm 0.004$ & 1.12 \\
\hline B60 & 10 & 48 & 2302 & $0.126 \pm 0.003$ & 0.98 \\
B60 & 20 & 48 & 2442 & $0.133 \pm 0.003$ & 0.97 \\
B60 & 30 & 48 & 2515 & $0.137 \pm 0.003$ & 0.94 \\
\hline
\end{tabular}

tE: etch time (5.5 $\mathrm{M} \mathrm{HNO}_{3}$ at $\left.21^{\circ} \mathrm{C}\right)$; Fields: microscope fields counted (3.815 $10^{4} \mu \mathrm{m}^{2}$ ); Counts: total tracks counted; $\rho$ s: track density; $\sigma / \sigma \mathrm{P}$ : ratio of the standard deviation of the track-density distribution to that of a Poisson distribution.

Table 2. Intercepts and slopes of geometric mean regression lines fitted to the corresponding track counts for 10, 20 and 30 s etching from Table 1.

85

\begin{tabular}{ccccc} 
Sample & Interval & Intercept & Slope & Correlation \\
\hline B00 & 10s-20s & 1.59 & 0.92 & 0.87 \\
B00 & $20 s-30 s$ & 1.55 & 0.91 & 0.95 \\
B00 & $10 s-30 s$ & 2.95 & 0.84 & 0.86 \\
\hline P00 & $10 s-20 s$ & 3.09 & 1.01 & 0.89 \\
P00 & 20s-30s & 4.03 & 0.95 & 0.95 \\
P00 & $10 s-30 s$ & 6.97 & 0.96 & 0.83 \\
\hline B60 & $10 s-20 s$ & 1.94 & 1.02 & 0.91 \\
B60 & $20 s-30 s$ & 2.49 & 0.98 & 0.95 \\
B60 & $10 s-30 s$ & 4.40 & 1.00 & 0.87 \\
\hline
\end{tabular}


tracks. The individual deviations are random: a track is lost in one field while one is added in a different field of the same sample. In general, however, track loss dominates in the basal face (B00), while tracks are gained in P00 an B60. The overall changes between 10 and $30 \mathrm{~s}$ amount to $\sim 10 \%$ of the initial values. The changes are smaller from 20 to $30 \mathrm{~s}$ etching than from 10 to $20 \mathrm{~s}$, but consistent with the initial trend. We interpret this as an indication, but not proof, of a decreasing surface etch rate, linked to decreasing polishing damage with increasing depth $\mathrm{Ku}-$ mar et al., 2013; Hicks et al., 2019). The corresponding track counts at 10, 20 and 30 s are little affected by random variation, and thus robust; the surface eth rate is therefore a factor meriting further attention.

Table 2 lists the intercepts and slopes of geometric mean regression lines fitted to the plots in Figure 1. For B00, the intercepts remain low while the slopes decrease with etch time. The inference that the loss is proportional to the track count is not obvious since higher track counts are not associated with higher uranium concentrations but due to random Poisson variation. We propose that the track loss is due to the growth and merger of the surface etch pits, which consume the shorter track channels causing losses proportional to the initial number of tracks in each field. For P00 and B60, the slopes remain constant at $\sim 1$ while the intercepts increase with etch time. A uniform increase, independent of the initial track count, suggests that on average tracks are added due to surface etching. Jonckheere et al. (2019; eqs. (1) and (2)) compared the conventional etch model (Tagami et al., 2005) with a lesser known one (Jonckheere and Van den haute, 1999) in terms of their effects on the track counts. The first predicts increasing track counts whereas the latter predicts constant counts. Despite its correct prediction, the first model was deemed inapplicable because it failed on other counts (Jonckheere et al., 2019; in press). In contrast to that model, in which no etched tracks are lost, the second model implies constant track counts because the rate at which tracks are added from surface etching equals that at which others are lost from the same cause. Tracks are added when the advancing surface catches their upper ends and lost when it overtakes their lower ends. However, before the surface reaches the lower termination of the latent track ( $t$; Figure 2$)$, its etch channel has increased in length. Around that point, the slow-etching faces ( $c d$ and $d e$ ) terminating the channel also come to intersect the surface. This alters the manner in which they are etched (cf. Figure 4 of Jonckheere et al., 2019), increasing their etch rates and allowing them, for a while, to keep ahead of the advancing surface (Figure 2). A residual etch figure can thus persist after the surface has overtaken the latent track. This phenomenon is more pronounced at low etchant concentrations (Jonckheere and Van den haute, 1996). This reconciles our new observations with the new etch model, while also explaining the fact that the net rate of addition is not much greater for B60 than for P00 despite its more than twice higher etch rate (Aslanian et al., 2021). 


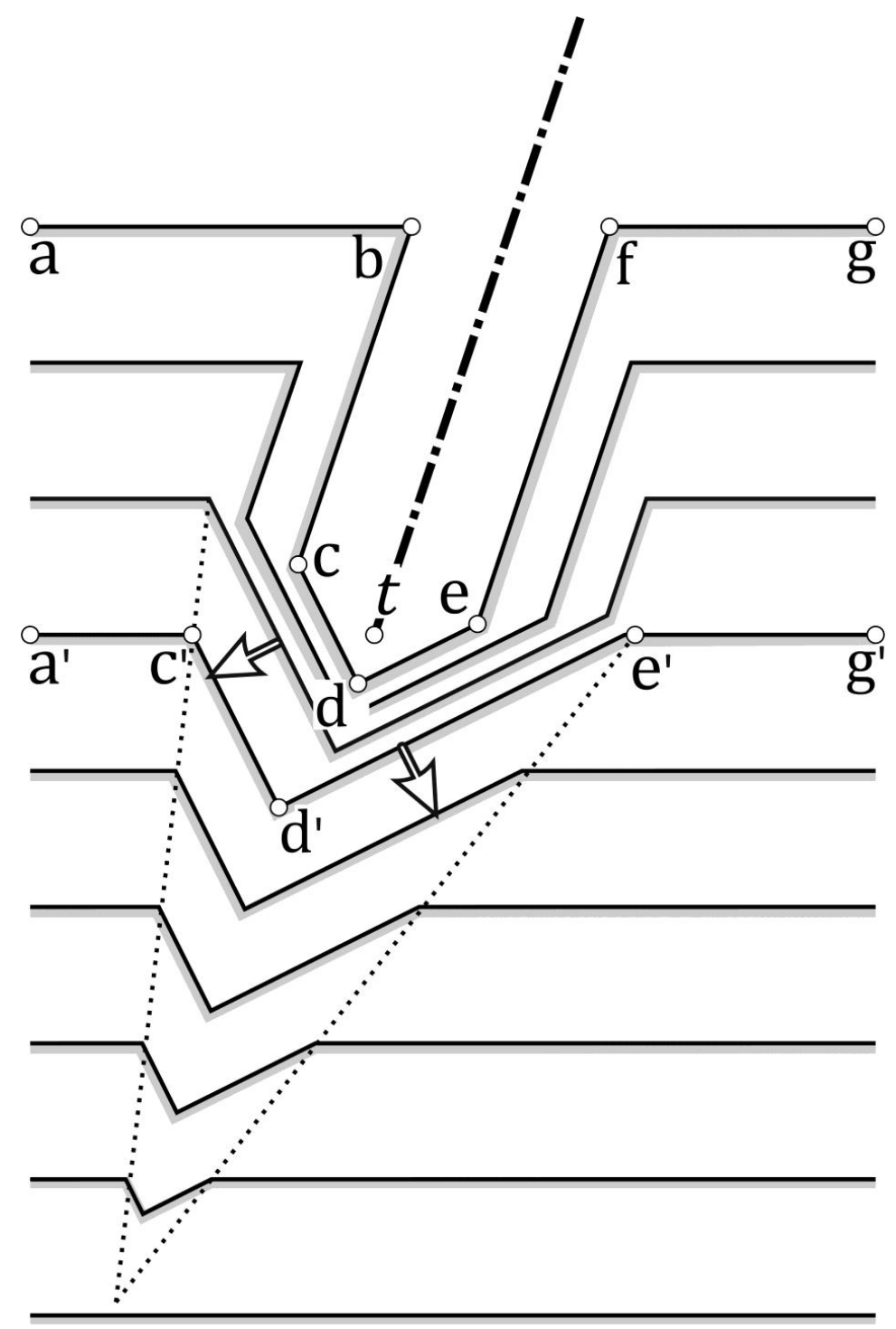

Figure 2. Principle of the persistence of an etch pit past the termination of a latent track. Before the advancing surface (a-b-f-g) overtakes the track at $t$, the faces (c-d-e) terminating the track channel have moved ahead, creating a feature that, depending on the etch rates of (c-de) and (a-b-f-g) can persist for a time. This duration is extended if (c-d-e) upon intersecting the surface acquire increased etch rates due to a change in the mechanism of etchant attack (white arrows). This mechanism accounts for the observed increases of the track counts in P00 and B60 within the etch model of Jonckheere et al. (2019; in press) and Aslanian et al. (2021). 
Figures 3a-c compares the sizes (long axes) of the track openings in B00, B60 and P00 at 10, 20 and $30 \mathrm{~s}$. Those in the basal (B00) and prism (P00) face have uniform size, reflected in a narrow distribution. With increasing etch time, the distributions shift to greater values and become leftskewed. We interpret this as due to tracks added as a result of surface etching. Insofar as the distributions are diagnostic, tracks are added at a decreasing rate, suggesting a declining surface etch rate. The openings in the intermediate face (B60) have a limited size range at $10 \mathrm{~s}$ but broad distributions at longer etch times. In contrast to basal and prism faces, the track openings in B60 do not have uniform shapes or orientations (Jonckheere et al., 2020). Their long axes therefore increase at different, orientation-dependent rates, stretching their size distribution. Figure $3 \mathrm{~d}$ plots the mean sizes of the track openings in B00, P00 and B60 as a function of etch time. Their growth rates are constant, but, whereas the track openings in P00 and B60 grow from the instant of immersion, there is a delay before the onset of etch pit growth in B00. This is also a consequence of a transient phase of accelerated surface etching due to superficial polishing damage.

Figure 4 illustrates the principle using two stages of the development of a track in a basal face (B00) and in a prism face, calculated with the model and apatite etch rates $\left(V_{R}\right)$ of Aslanian et al. (2021) and Jonckheere et al. (in press). The two steps are of equal duration and the etch rates are constant, except for the surface etch rate $(v s)$, taken to be three times higher during the first stage. The shallow etch pit at the track intersection with a basal face causes the size increase of the track openings to be suppressed during the initial stage of accelerated surface etching (Figure 4a). After the surface etch rate drops to the normal value during the second stage, the etch pit diameter grows at the actual rate determined by the intrinsic apatite etch rates, increasing in size by a factor of almost three. An increased surface etch rate has no such effect on the track openings in a prism or intermediate surface because in most cases the tracks lack an etch pit (Jonckheere et al., in press). The width of the track opening between the parallel channel walls is unaffected by surface etching and increases in direct proportion to the immersion time (Figure $4 b$ ).

For the second experiment, we cut fourteen prism sections from a crystal of Durango apatite. We annealed half at $450^{\circ} \mathrm{C}$ for 24 hours to erase the fossil tracks; the other half retained their full complement of fossil tracks. The annealed sections were irradiated with thermal neutrons in channel Y4 of the BR1 reactor of the Belgian Nuclear Research Center (SCK•CEN; $\phi$ тн $\approx 10^{16}$ $\mathrm{cm}^{-2}$ ) to produce induced fission tracks. A section with fossil tracks was paired with one containing induced tracks and annealed for $24 \mathrm{~h}$ at temperatures of 183, 231,171, 291, 304 and $313^{\circ} \mathrm{C}$; the remaining sections were not annealed. The samples were mounted in resin, ground 

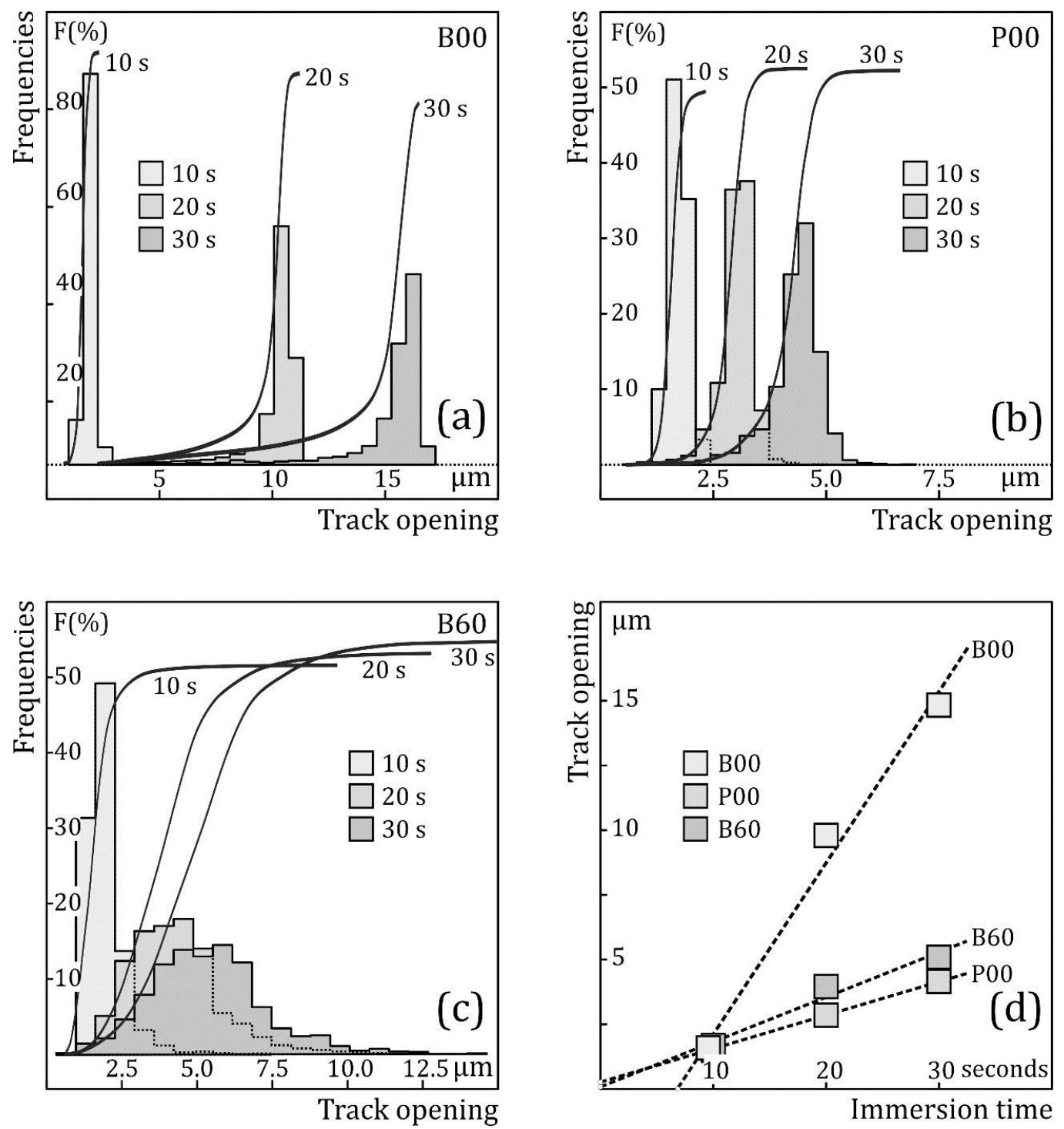

Figure 3. Histograms and cumulative frequencies (solid lines; $g$-spectra, Jonckheere et al., 2020) of the sizes (long axes) of the track openings in (a) a basal face, (b) a prism face, and (c) a face at $30^{\circ}$ to a prism face of Durango apatite after 10, 20 and $30 \mathrm{~s}$ etching $\left(5.5 \mathrm{M} \mathrm{HNO}_{3}\right.$ at $21^{\circ} \mathrm{C}$ ); (d) the mean sizes plotted against etch time show a constant rate of increase in the three surfaces. 

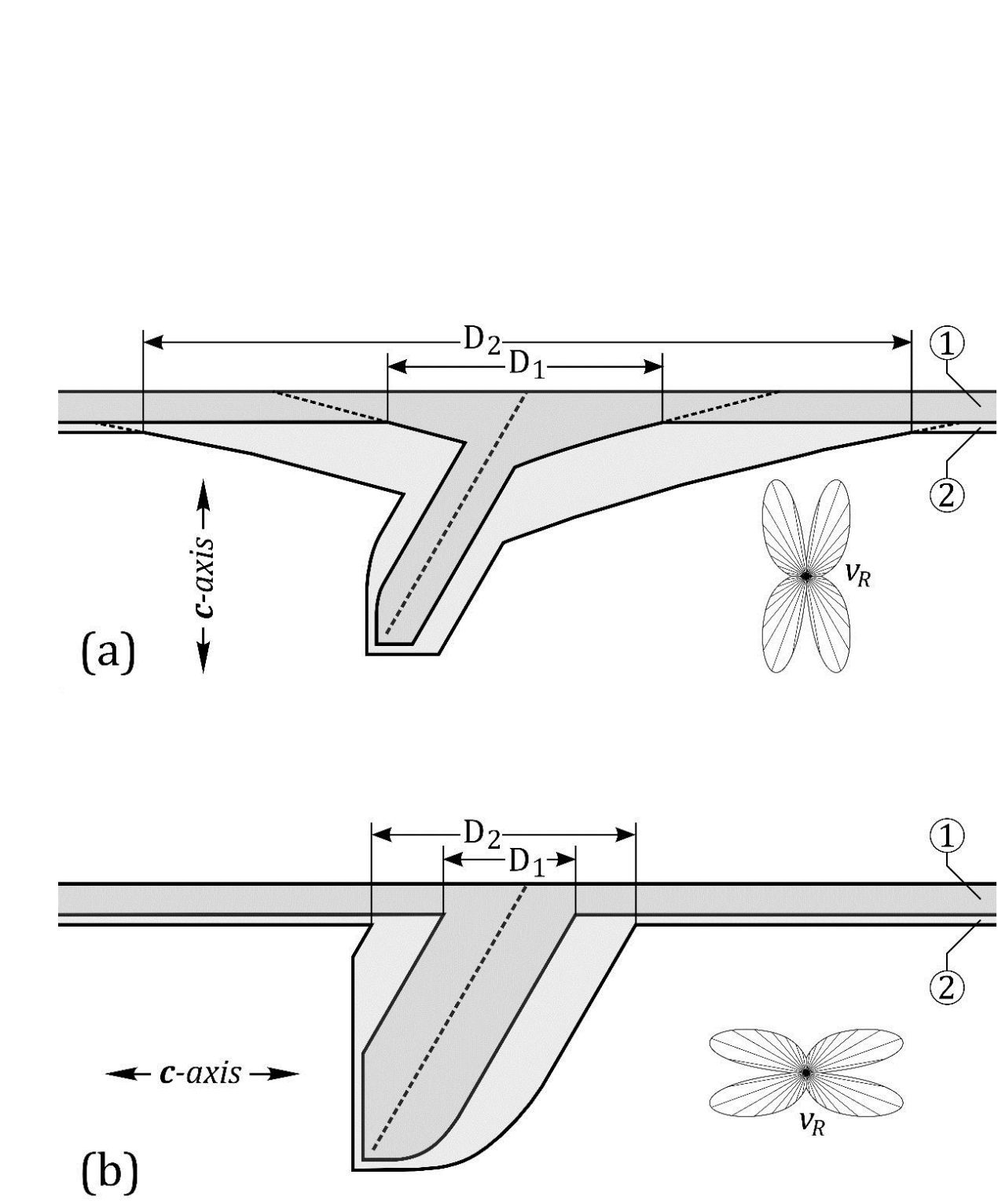

Figure 4. Sketch of the consequences of an initial phase of accelerated surface etching on the size increase of the surface-track intersections in an apatite basal face (a) and prism face (b). The etch rates $\left(v_{R}\right)$ represented in the etch rate plot (right inset; Aslanian et al., 2021) are assumed constant, except for a three-fold higher surface etch rate $(v s)$ during the first of two stages; (1): first stage: $v_{s}=1.5 \mu \mathrm{m} / \mathrm{min}$; (2): second stage: $v_{s}=0.5 \mu \mathrm{m} / \mathrm{min}$; the etch rate plot is not to scale. 
to expose internal surfaces and polished with 6, 3 and $1 \mu \mathrm{m}$ diamond suspensions and 0.04 $\mu \mathrm{m}$ silica suspension to the highest standard achievable with our equipment and expertise. Each mount was foreseen with a system of reference points and etched for $20 \mathrm{~s}$ in $5.5 \mathrm{M} \mathrm{HNO}_{3}$ at $21^{\circ} \mathrm{C}$. Our samples also included four prismatic sections of Durango apatite acquired for an inter-lab comparison. The pre-annealing, neutron irradiation and partial annealing conditions are given in Ketcham et al. (2015). The apatite sections were mounted, ground and polished as described. We performed track counts in the same fields in transmitted light and reflected light, using a Zeiss Z2m microscope and Märzhäuser motorized stage connected to a desktop computer. The Autoscan software was used for stage control and recording the positions of the counted fields but the track counts were done at the microscope at an overall magnification of $800 \times$.

Figure 5 shows reflected-light (RL) and transmitted-light (TL) images of the same areas in one unannealed section and five with different degrees of partial annealing. The RL images reveal numerous near-identical features. Most, but not all, correspond to the openings of unmistakable fission-track channels in the TL images of samples annealed at up to $271^{\circ} \mathrm{C}$. The mismatch increases for the more annealed samples, in which the number of identifiable track channels under TL decreases faster than the RL features. We counted these features on the assumption that they represent the surface intersections of long (with channel) or short (without channel) etched segments of intermittent latent fission tracks (Gleadow et al., 1983; Green et al., 1986; Paul and Fitzgerald, 1992; Paul, 1993; Li et al., 2011; 2012; 2014; Wauschkuhn et al., 2015).

185 Table 3 and Figure 6 compare the RL and TL counts of the same areas. There is a close correlation between the RL and TL counts up to $271^{\circ} \mathrm{C}$, with the former 5-10 \% higher for both fossil and induced tracks and across the investigated range of track densities (TL: 0.127-2.923 $10^{6}$ $\mathrm{cm}^{-2}$; RL: 0.134-3.016 $10^{6} \mathrm{~cm}^{-2}$ ). The TL counts collapse at higher temperatures while the RL counts remain almost constant in comparison. The transition from consistent to inconsistent 190 RL- and TL counts occurs at the point $\left(\rho / \rho_{0} \approx 0.70\right)$ at which tracks at high angles to the $c$-axis break up in shorter etchable segments separated by unetchable gaps (Watt et al., 1984; Green et al., 1986) or are subject to accelerated length reduction (Donelick et al., 1999). It is worth noting that, with few exceptions, the RL and TL counts have standard deviations close to those of the Poisson distribution $\left(\sigma / \sigma_{\mathrm{P}} \approx 1\right)$, irrespective of the ratio of the RL to TL track counts, as 195 expected for the products of a radioactive process. It is improbable that defect swarms possess statistical properties indistinguishable from those of the fission tracks in the same samples. 

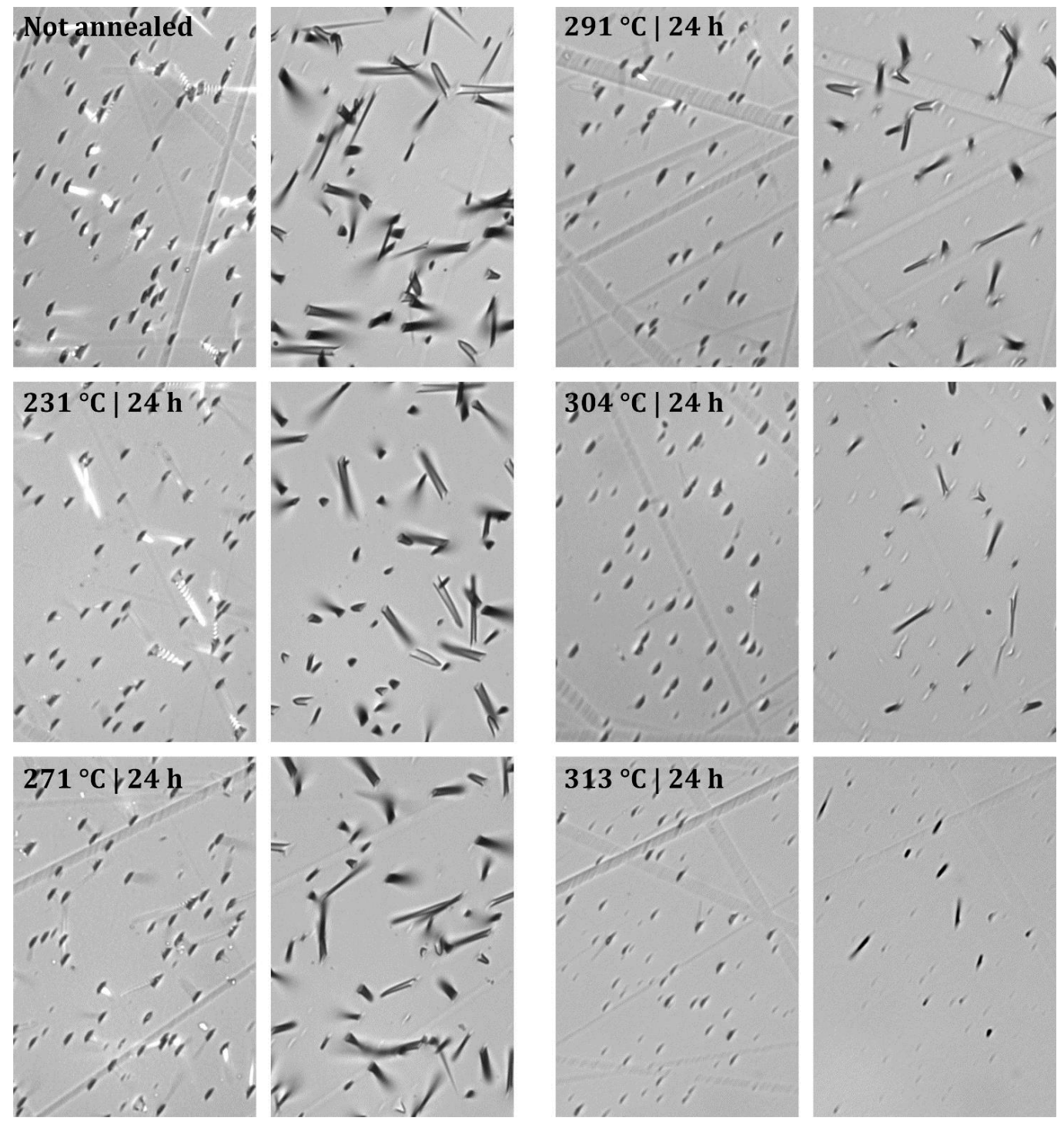

Figure 5. Pairs of reflected-light (RL; left) and transmitted-light (TL; right) images of the same areas in prism faces of an unannealed apatite and five annealed under different $(T, t)$ conditions. All samples contain induced fission tracks and were etched for $20 \mathrm{~s}$ in $5.5 \mathrm{M} \mathrm{HNO}_{3}$ at $21^{\circ} \mathrm{C}$. 


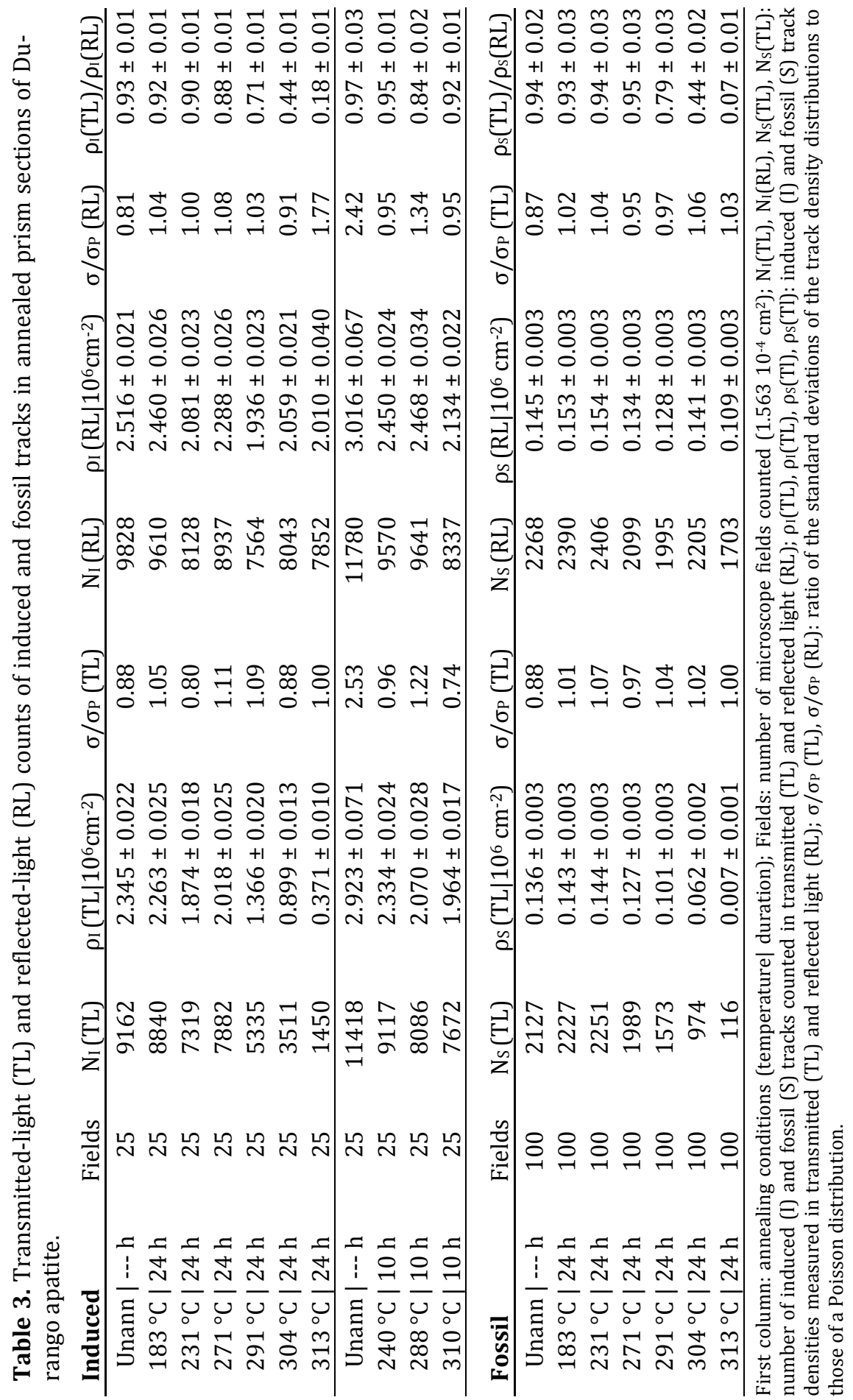




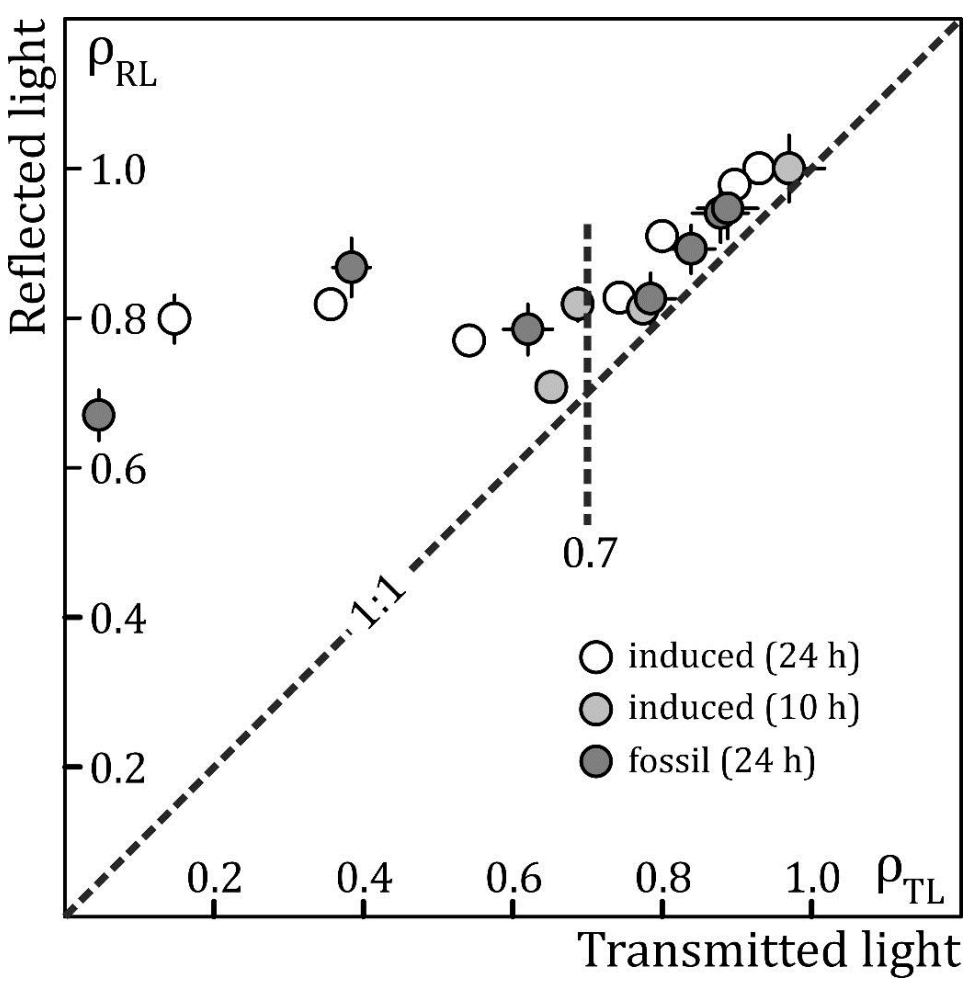

Figure 6. Fossil and induced track densities in prism faces of Durango apatite determined using reflected light ( $\rho_{\mathrm{RL}}$ ) plotted against those measured in the same counting areas using transmitted light $(\rho \mathrm{TL})$. The samples were annealed under different $(\mathrm{T}, \mathrm{t})$-conditions, summarised in Table 3, polished to a final high finish with $0.04 \mu \mathrm{m}$ silica suspension, and etched for $20 \mathrm{~s}$ in 5.5 $\mathrm{M} \mathrm{HNO}_{3}$ at $21^{\circ} \mathrm{C}$. The induced track densities are normalized to those of the unannealed samples, those of the fossil tracks to $0.89 \times$ that of the unannealed sample, to account for natural annealing. 


\section{Discussion and Conclusions}

We submit this contribution from a concern that, while the tools for interpreting fission-track data are evolving, the calculated ages, age components and thermal histories are only as good as the track counts and the measured track lengths. Measuring and counting fission tracks requires etching to make them accessible for microscopic examination. Track etching is often considered as an inconsequential sample preparation step. However, recent studies that have again taken up the twin issues of etching and observation confirm that both have an effect on confined track lengths (Jonckheere et al., 2007; 2017; Tamer et al., 2019; Tamer and Ketcham, 2020; Aslanian et al., 2021; Ketcham and Tamer, 2021). Our results show that etching and observation also have consequences for the track counts, which we cannot be confident of evading by selecting apatite prism faces and adopting the $\zeta$-calibration for age calculations. Besides being inadequate for the purpose, both measures have drawbacks. Selecting prism (scratched) faces for dating often implies that a large fraction of the grains in a mount is ignored. This can lead to reduced grain counts, which is a particular problem for distinguishing age components in a mixture. Grain selection based on shape can also cause an age component to be missed. The drawbacks of the $\zeta$-calibration are of a different nature (Hurford, 1998; Enkelmann et al., 2005; Jonckheere et al., 2015; Iwano et al., 2018; 2019): $\zeta$ is an efficient workaround for the calibration problem, but it is just that: it circumvents difficulties without eliminating them. It has to be taken on trust that it deals with all etching- and counting-related factors under all circumstances.

Our findings provide no solution. It is doubtful that here is a single solution for all polishing, etching and counting protocols, or for all samples. Our results do illustrate how simple experiments throw light on the factors affecting the track counts, and, thence, the sample ages. This is relevant to the advantages and disadvantages of manual and automatic track counts (Gleadow et al., 2009; 2019; Enkelmann et al., 2012) and to designing training strategies for neural networks (Nachtergaele and De Grave, 2021). It is, in general, useful for valuating the input, and thus the output, of modelling programs. Grain orientation, polishing finish, etching conditions (time) and observation method are all shown to influence the fission-track counts in apatite. Prism faces are not unproblematic for counting and other orientations are not per se useless. Faster-etching surfaces, in which etch pits do not form at the track-surface intersections (Jonckheere et al., 2020, 2022) can indeed present practical advantages, in addition to the numerical advantage of including them. Their fission-track properties are the subject of ongoing studies. Our results also support the fact that fossil and induced fission tracks are discontinuous towards their tips and that individual segments remain etchable after annealing and break-up. 
GC supplement.xlsx.

\section{Author contributions.}

BW and RJ made the samples, CA and RJ performed the measurements. CA, RJ, BW and LR compiled and interpreted the data, prepared the tables and figures and wrote the manuscript.

\section{Competing interests.}

The authors declare that they have no conflict of interest.

\section{Acknowledgements}

Financial support

Research funded by the German Research Council (projects Jo 358/4-1 and Wa 4390/1-1).

\section{References}

Aslanian, C., Jonckheere, R., Wauschkuhn, B., and Ratschbacher, L.: A quantitative description of fission-track etching in apatite. American Mineralogist, 106, 518-526, 2021.

Bhandari, N., Bhat, S. G., Lal, D., Rajagopalan, G., Tamhane, A. S. J., and Venkatavaradan, V. S.: Fission fragment tracks in apatite: recordable track lengths. Earth and Planetary Science Letters, 13, 191-199, 1971.

Donelick, R. A., Ketcham, R. A., and Carlson, W. D.: Variability of apatite fission-track annealing kinetics: II. Crystallographic orientation effects. American Mineralogist, 84, 1224-1234, 1999.

Enkelmann, E., Ehlers, T. A., Buck G., Schatz A.-K.: Advantages and challenges of automated apatite fission track counting. Chemical Geology, 322-323, 278-289, 2012.

Enkelmann, E., Jonckheere, R., and Wauschkuhn, B.: Independent fission-track ages ( $\phi$-ages) of proposed and accepted apatite age standards and a comparison of $\phi^{-}, \mathrm{Z}-, \zeta$ - and $\zeta_{0}$-ages: Implications for method calibration. Chemical Geology, 222, 232-248, 2005.

Gleadow, A. J. W., Duddy, I. R., and Lovering, J. F.: Fission-track analysis: A new tool for the evaluation of thermal histories and hydrocarbon potential. Journal of the Australian Petroleum Production and Exploration Association, 23, 93-102, 1983.

Gleadow, A. J. W., Gleadow, S. J., Belton, D. X., Kohn, B. P., Krochmal, M. S., and Brown, R. W.: Coincidence mapping - a key strategy for the automatic counting of fission tracks in natural minerals. Geological Society of London, Special Publications, 324, 25-36, 2009.

Gleadow A., Kohn B., and Seiler C.: The future of fission-track thermochronology, in: Malusà, M. G., and Fitzgerald, P. G. (eds.), Fission-Track Thermochronology and its Application to Geology, Springer Textbooks in Earth Sciences, Geography and Environment, 77-92, 2019.

Green, P. F., Duddy, I. R., Gleadow, A. J. W., Tingate, P. R., and Laslett, G. M.: Thermal annealing of fission tracks in apatite 1. A qualitative description. Chemical Geology (Isotope Geoscience Section), 59, 237-253, 1986.

Hicks, M.-L., Pakpour-Tabrizi, A. C., Jackman, R. B.: Polishing, preparation and patterning of diamond for device applications. Diamond and Related Materials, 97, 107424, 2019.

Hurford, A. J.: Standardization of fission track dating calibration. Recommendation by the Fission Track Working Group of the I.U.G.S. Subcomission on Geochronology. Chemical Geology (Isotope Geoscience Section), 80, 171-178, 1990.

Hurford, A. J.: Zeta: the ultimate solution to fission track analysis calibration or just an interim measure? In: Van den haute, P., and De Corte, F., (eds.), Advances in fission-track geochronology, 19-32. Kluwer Academic Publishers, 1998.

Iwano, H., Danhara, T., and Hirata, T.: Standardless fission-track ages of the IUGS age standards. Chemical Geology, 488, 87-104, 2018. 
Iwano, H., Danhara, T., Yuguchi, T., Hirata, T., Ogasawara, M.: Duluth Complex apatites: Age reference material for LA-ICP-MS-based fission-track dating. Terra Nova, 31, 247-256, 2019.

Jonckheere, R.: On the densities of etchable fission tracks in a mineral and co-irradiated external detector with reference to fission-track dating of minerals. Chemical Geology, 200, 41-58, 2003.

Jonckheere, R., Aslanian, C., Wauschkuhn, B., and Ratschbacher, L.: Some geometrical properties of fission-tracksurface intersections in apatite. American Mineralogist, 105, 1355-1364, 2020.

Jonckheere, R., Aslanian, C., Wauschkuhn, B., and Ratschbacher, L.: Fission-track etching in apatite: A model and some implications. American Mineralogist, 107, https://doi.org/10.2138/am-2022-8055.

Jonckheere, R., Enkelmann, E., Min, M., Trautmann, C., and Ratschbacher, L.: Confined fission tracks in ionirradiated and step-etched prismatic sections of Durango apatite. Chemical Geology, 242, 202-217, 2007.

Jonckheere, R., Tamer, M. T., Wauschkuhn, B., Wauschkuhn, F., and Ratschbacher, L.: Single-track length measurements of step-etched fission tracks in Durango apatite: "Vorsprung durch Technik". American Mineralogist, 102, 987-996, 2017.

Jonckheere, R., and Van den haute, P.: Observations on the geometry of etched fission tracks in apatite: implications for models of track revelation. American Mineralogist, 81, 1476-1493, 1996.

Jonckheere R., and Van den haute, P.: On the frequency distributions per unit area of the projected and etchable lengths of surface-intersecting fission tracks: Influences of track revelation, observation and measurement. Radiation Measurements, 30, 155-179, 1999.

Jonckheere, R., Van den haute, P., and Ratschbacher, L.: Standardless fission-track dating of the Durango apatite age standard. Chemical Geology, 417, 44-57, 2015.

Jonckheere, R., Wauschkuhn, B., and Ratschbacher, L.: On growth and form of etched fission tracks in apatite: A kinetic approach. American Mineralogist, 104, 569-579, 2019.

Ketcham, R. A., Carter A., and Hurford A. J.: Inter-laboratory comparison of fission track confined length and etch figure measurements in apatite. American Mineralogist, 100, 1452-1468, 2015.

Ketcham, R. A., and Tamer, M. T.: Confined fission-track revelation in apatite: how it works and why it matters. Geochronology, 3, 433-464, 2021.

Kumar, P., Lee, J., Lee, G., Rao, S., Singh, D., Singh, R. K.: Low temperature wet etching to reveal sub-surface damage in sapphire substrates. Applied Surface Science, 273, 58-61, 2013.

Li, W., Kluth, P., Schauries, D., Rodriguez, M. D., Lang, M., Zhang, F., Zdorovets, M., Trautmann, C., and Ewing, R. C.: Effect of orientation on ion track formation in apatite and zircon. American Mineralogist, 99, 1127-1132, 2014.

Li, W., Lang, M., Gleadow, A. J. W., Zdorovets, M. V., and Ewing, R. C.: Thermal annealing of unetched fission tracks in apatite. Earth and Planetary Science Letters, 321-322, 121-127, 2012.

Li, W., Wang, L., Lang, M., Trautmann, C., and Ewing, R. C.: Thermal annealing mechanisms of latent fission tracks: Apatite vs. zircon. Earth and Planetary Science Letters, 302, 227-235, 2011.

Nachtergaele, S., and De Grave, J.: AI-Track-tive: open-source software for automated recognition and counting of surface semi-tracks using computer vision (artificial intelligence). Geochronology, 3, 383-394, 2021.

Paul, T. A.: Transmission electron microscopy investigation of unetched fission tracks in fluorapatite - physical process of annealing. Nuclear Tracks and Radiation Measurements, 21, 507-511, 1993.

Paul, T. A., and Fitzgerald, P. G.: Transmission electron microscopic investigation of fission tracks in fluorapatite. American Mineralogist, 77, 336-344, 1992.

Tagami, T., and O'Sullivan, P. B.: Fundamentals of fission-track thermochronology. Reviews in Mineralogy and Geochemistry, 58, 19-47, 2005.

Tamer, M. T., Chung, L., Ketcham, R. A., and Gleadow, A. J. W.: Analyst and etching protocol effects on the reproducibility of apatite confined fission-track length measurement, and ambient-temperature annealing at decadal timescales. American Mineralogist, 104, 1421-1435, 2019.

Tamer, M. T., and Ketcham, R. A.: The along-track etching structure of fission tracks in apatite: Observations and implications. Chemical Geology, 553, 119809, 2020.

Wauschkuhn, B., Jonckheere, R., and Ratschbacher, L.: Xe- and U-tracks in apatite and muscovite near the etching threshold. Nuclear Instruments and Methods B 343, 146-152, 2015.

Watt S., Green P. F., and Durrani S. A.: Studies of annealing anisotropy of fission tracks in mineral apatite using track-in-track (tint) length measurements. Nuclear Tracks and Radiation Measurements, 8, 371-375, 1984. 